\title{
A Real-Life Study of New Antiviral Therapies in a High Prevalence Geographical Area for Hepatitis C Virus Infection
}

\author{
Alessandro Federico ${ }^{1,}{ }^{*}$, Marcello Dallio ${ }^{1}$, Giuseppe Gerardo Caprio ${ }^{1}$, Ilario de Sio $^{1}$, Gaetano Cotticelli ${ }^{1}$, \\ Pasquale Esposito ${ }^{1}$ and Carmelina Loguercio ${ }^{1}$
}

${ }^{1}$ Hepatogastroenterology Division, University of Campania "L. Vanvitelli", Naples, Italy

"Corresponding author: Hepatogastroenterology Division, University of Campania "L. Vanvitelli", Naples, Italy. Tel: +39-815666723, E-mail: alessandro.federico@unicampania.it Received 2018 May 02; Revised 2018 August 11; Accepted 2018 August 13.

\begin{abstract}
Background: Hepatitis C virus (HCV) infection represents one of the most important causes of chronic liver damage. The development of new therapeutic approaches based on the use of direct-acting antivirals allowed reaching the high rates of sustained virological response and on the other hand, the low rates of drug side effects.

Objectives: The study aimed to evaluate the efficacy and safety of multiple direct-acting antiviral (DAA) therapies against the major HCV genotypes in Campania.

Methods: We enrolled, in this monocentric observational study, 518 adult patients ( $>$ 18-years-old) affected by HCV who received a DAA anti-HCV-based therapy in the routine clinical practice. We collected direct data registered by the Hepatogastroenterology Division of the University of Campania "L. Vanvitelli", which covers a catchment area from the entire Campania region.

Results: A great number (98.2 \%) of the 518 enrolled patients was naive to the antiviral treatment and genotype distribution was $1 \mathrm{a}=32(6.2 \%), 1 \mathrm{~b}=252(48.7 \%), 2=146(28.2 \%), 3=52(10.1 \%)$, and $4=36(6.9 \%) .300$ patients were cirrhotic (57.9\%) and most of them had a Child-Pugh A5 score. $79.56 \%$ of the patients belonging to the population of our study were classified as fibrosis Metavir F3 or F4 by Fibroscan. All the enrolled patients completed the treatment with the exception of five $(n=5 ; 0.96 \%)$ who interrupted it due to adverse events. We observed a relapse of infection in three patients treated with Sofosbuvir and Simeprevir for 12 weeks (0.57\%). Intention to treat analysis showed an overall rate of $98.46 \%(n=510 / 518)$ sustained virological response. Six of the eight failure patients had a second line anti-HCV treatment and four of them obtained SVR (two patients are waiting for resistance test results). Conclusions: New antiviral regimens of DAA-based for HCV represent one of the greatest innovations in the scientific context in the last few years. Our prospective observational study confirms the elevated efficacy in terms of SVR12, independently from HCV genotype and disease stage, when these treatments are used as the methods of a good clinical practice.
\end{abstract}

Keywords: Viral Hepatitis, Direct-Acting Antivirals, Sustained Virological Response, Sustained Virological Response

\section{Background}

In 2015, the World Health Organization (WHO) estimated 71 million people affected by hepatitis $\mathrm{C}$ virus (HCV) worldwide that represents about $1 \%$ of the world inhabitants (1). This pathology is the cause of more than 400000 death per year because of complications related to the progression of the disease, such as cirrhosis and its complications or hepatocellular carcinoma (HCC) (1). The distribution of HCV prevalence, which is different among several considered geographical areas, is currently known. However, many of these data represent only a theoretical evaluation rather than the real-life situation because of a large number of patients living in the world areas where it is difficult to get epidemiological information. Italy, Romania, Spain, Germany, France, United King- dom, Poland, Greece, and Bulgaria are the countries in which there are more than $80 \%$ of the patients affected by HCV in Europe (2). Currently, a small number of data sets are available on the epidemiology of HCV infection in Italy (3-6). However, the known data demonstrate a prevalence of seropositivity for HCV that is higher in the Southern areas (7.3\%), Central island (6.1\%), and Northern ones (about 1.6\%) (4). In this setting, Campania represents a region with a high prevalence of HCV infection, as demonstrated by data concerning the number of directacting antiviral (DAA) prescriptions since the beginning of their use (http://www.aifa.gov.it/content/aggiornamentoepatite-c). The population size of the Campania region is about six million inhabitants and the main risk factors for HCV transmission are a history of surgical interventions or 
dental surgery and at least one previous blood transfusion or injective drug use. Few patients had an anamnesis of accidental puncture or tattoo/piercing. Finally, another little percentage of patients were born from an HCV-positive mother (7).

The history of HCV therapy in recent past years has been characterized by a succession of pharmacological innovations, which led us to obtain high healing rates. The association of Interferon (IFN) and Ribavirin (RBV) has been essential for the treatment of people affected by this pathology for a long time $(8,9)$. However, the therapeutic achievement was limited: in fact, it worked in about 50\% of the patients affected by HCV genotype $1.80 \%$ of those affected by HCV genotype 2, and $65 \%$ of those affected by genotype 3. Moreover, a higher rate of side effects related to the use of IFN was present. For these reasons, there was a difficulty in treating ill people with these drugs. In fact, the identification of predictive factors of therapy response has been often necessary. For example, some daily dietary components, evaluated by a nutritional assessment, such as unsaturated fatty acids, iron, zinc, vitamin A, and niacin and alcohol intake, were significantly different between responder and non-responder patients to IFN therapy. Genotype, age, body mass index, steatosis, and fibrosis were independent predictors of therapy outcomes (10).

Furthermore, the rapid virological response (RVR) was demonstrated to be the strongest predicting factor of sustained virological response (SVR) and infection with HCV genotype 2 was significantly associated with high RVR rate (11). In 2011, DAAs non-structural protein (NS) 3/4A proteases inhibitors, Telaprevir and Boceprevir, were approved to treat HCV genotype 1 infection along with pegylated IFN and RBV (12) reaching eradication rates of about $70 \%$ in chronic hepatitis $C$ infected patients. However, this therapy has caused a dramatically significant increase in side effects in addition to those that were already associated with IFN and RBV use, particularly anemia and skin adverse events (13). The second and third generation DAA introduced in 2013 - 2014 improved the efficacy and the tolerance of anti-HCV treatment $(14,15)$, with SVR rates of 90 - 95\%. The evolution of antiviral regimens has led to the development of pangenotypic drugs and a shorter treatment with a small number of tablets (up to daily monoadministration). Therefore, an elevated efficacy is the reason why it is possible to accept the pharmacoeconomic model elaborated to cure the infection (16). Even if new DAA regimens are characterized by SVR percentages, obtained by recording trials and real-life ones, which include $90-95 \%$ of the treated patients, the question concerning 5 $10 \%$ of patients who fail the first line treatment is yet open. $\mathrm{HCV}$ is able to modify its genetic structure in order to acquire resistance against new generation drugs, especially during antiviral therapy (17-19). The most frequent mutations occur in the genic region, which codifies for NS5A, infrequently for the NS3 and NS4A regions and NS5B ones. Therefore, it is necessary to start a second line treatment according to information obtained through specific resistance tests. In fact, NS3 mutations can persist for a limited time after the therapeutic failure; on the other hand, other mutations can also persist for several years after its resolution (17).

\section{Objectives}

We have chosen to carry on a monocentric real-life analysis of DAA treatments prescribed from 2015 to 2017. Specifically, we focused on demographical features of treated patients, genotype distribution, the efficacy of prescribed treatments in accordance with guidelines and resistance rates for each treatment used in a specific geographical area with a particular prevalence for HCV.

\section{Methods}

\subsection{Patients}

We enrolled, in this monocentric observational study, 518 adult patients ( $\geq$ 18-years-old) affected by HCV who received a DAAs anti-HCV-based therapy in the routine clinical practice. We collected direct data registered by the Hepatogastroenterology Division of the University of Campania "L. Vanvitelli", which covers a catchment area from the entire Campania region. We submitted an informed consent for every enrolled patient. All patients started antiviral therapy between March 2015 and July 2017 and they were included in the analysis. The decision to treat and the choice of the drugs were taken by the physician. The therapeutic regimen, duration, or addition of RBV was indicated according to the current drug availability and clinical recommendations (20). We decided on the RBV dosage according to the weight of the patient and the dose modification was based on the reduction of hemoglobin and the comorbidities of the patients. The selected patients were treatment-naive or IFN-based treatment experienced. Cirrhosis was defined based on a liver biopsy end/or a liver stiffness measurement (Fibroscan) $\geq 14 \mathrm{kPa}$, or the presence of other known clinical signs of portal hypertension, such as esophageal varices or clinical decompensation (ascites or hepatic encephalopathy). Exclusion criteria were human immunodeficiency virus (HIV) or hepatitis B virus coinfection, refusal to give consent to data registry, or an incompatibility between the antiviral therapy beginning and the health status of the patient. 


\subsection{Comorbidities and Concomitant Medications}

Baseline comorbidities, such as chronic obstructive pulmonary disease, diabetes mellitus, cardiovascular diseases, arterial hypertension, arrhythmia, depression, and history of extrahepatic malignancy, were recorded. In addition, the medications taken by the patients at baseline were registered. The drugs interactions were evaluated according to drug label information or the University of Liverpool website (http://www.hep-druginteractions.org/). We interrupted the use of concomitant medications that were impossible to be coadministrated with antivirals or replaced them with equivalent drugs.

\subsection{Efficacy and Safety Analysis}

The efficacy primary endpoint was assessed by the percentage of patients with SVR12, defined as an HCV-RNA $<15$ $\mathrm{IU} / \mathrm{mL}, 12$ weeks after the last dose of antiviral medication. HCV-RNA levels were measured using the Roche TaqMan real-time reverse transcriptase-PCR assay version 2.0 with a lower limit of quantification and detection of $15 \mathrm{IU} / \mathrm{mL}$. Secondary assessments included the percentage of patients with treatment virological failure and post-treatment relapse. Virological breakthrough was defined in case of the identification of an increase at the HCV-RNA level of at least $1 \log \mathrm{IU} / \mathrm{mL}$ or a confirmed quantifiable HCV-RNA level following undetectable HCV-RNA during treatment. Treatment-emergent adverse events and premature treatment discontinuations during the treatment period were recorded.

\subsection{Statistical Analysis}

A descriptive analysis was performed for all variables. Continuous variables were reported as means \pm standard deviations or median (range), as indicated. For dichotomous/categorical variables, absolute numbers and percentages were computed. The comparison of quantitative parameters was carried out using Student's t/MannWhitney test, as appropriate. The association between qualitative variables was assessed using the Chi-square statistic. An intention to treat analysis (ITT) was done to evaluate SVR12. Statistical analysis was performed using SPSS for Windows (version 19.0, SPSS Inc., Chicago, Illinois).

\section{Results}

\subsection{Analyzed Population}

During the evaluation period, 518 consecutive patients, who met all the inclusion criteria for the study, were enrolled at the Hepatogastroenterology Division of the University of Campania "Luigi Vanvitelli" in Naples (Italy).
They were treated according to the current drug availability and clinical recommendations (20) with different antiviral therapies based on DAA use. A patient died during the treatment for reasons that did not concern the therapy (car accident). Moreover, no serious adverse events related to the treatment were registered, with the exception of a unique case, later discussed, in which we had to interrupt the therapy with Ombitasvir/Paritaprevir/Ritonavir plus Dasabuvir plus RBV after 30 days from the beginning of the treatment for sudden worsening of liver functionality parameters evaluated (bilirubin, albumin, and prothrombin time).

The baseline characteristics of the enrolled patients are summarized in Table 1 . The patients were all Caucasian and resident in Campania. The mean age was $66.40 \pm 11.01$ years; there were more women (315) than men (203), and there was a median body mass index (BMI) in mild overweight. Most of them were naive to an antiviral treatment (98.2\%) against HCV and presented a genotype $1 \mathrm{~b}$ infection. The treatment used for each genotype is shown in Figure 1. enrolled patients were classified as cirrhotic and most of them had a Child-Pugh A5 score. No patient decompensated cirrhosis or HCC. 79.56\% of the patients belonging to the population in our study were classified as fibrosis Metavir F3 or F4 by Fibroscan. Moreover, only a small percentage of them had esophageal varices (F1: 12\%; F2: 5\%; F3: $1.3 \%)$.

\subsection{Efficacy and Safety}

The SVR12 rate is reported in Table 2. Out of 16 patients treated with Sofosbuvir and RBV for 24 weeks, 15 (93.7\%) responded to the treatment, whereas only one patient interrupted the therapy due to the worsening of the major depressive disorder diagnosed prior to the beginning of antiviral treatment. 95 patients were treated with Sofosbuvir plus Simeprevir for 12 weeks, among whom 92 (96.8\%) reached SVR12 and three (3.81\%) had a relapse. The treatment with Sofosbuvir plus Lepidasvir for 24 weeks was realized in 130 patients; three of them (2.3\%) suspended the therapy: one patient for a traumatic death not correlated to the treatment (car accident) and two patients for the adverse effects onset. Specifically, for one of those patients, we observed a worsening of major depressive disorder diagnosed prior to the beginning of the therapy. It was not necessary to conduct any adjustment of antidepressive therapy to treat it. The other patient interrupted not for a medical condition in accordance with the antiviral therapy but for the inguinal subepidermic appearance of vesicula. Out of 47 patients treated with Ombitasvir/Paritaprevir/Ritonavir plus Dasabuvir plus RBV for 12 weeks, only one patient (2.2\%) interrupted for adverse effects correlated to the therapy: after 30 days from 


\begin{tabular}{|c|c|}
\hline Variable & Study Population N = 518 \\
\hline $\mathbf{M} / \mathbf{F}^{\mathbf{a}}$ & $203(39.1) / 315(60.9)$ \\
\hline Age, $y^{b}$ & $66.40 \pm 11.0$ (range: 31 - 38) \\
\hline BMI, $\mathbf{k g} / \mathrm{m}^{2 b}$ & $26.89 \pm 3.95$ \\
\hline HCV-RNA, UI/mL ${ }^{\mathrm{b}}$ & $1.826 .577 \pm 2.711 .718$ \\
\hline \multicolumn{2}{|l|}{ Genotype $^{\mathrm{a}}$} \\
\hline 1a & $32(6.2)$ \\
\hline $1 \mathrm{~b}$ & $252(48.7)$ \\
\hline 2 & $146(28.2)$ \\
\hline 3 & $52(10.1)$ \\
\hline 4 & $36(6.9)$ \\
\hline \multicolumn{2}{|l|}{ Previous treatment $^{\mathrm{a}}$} \\
\hline Naive & $373(72)$ \\
\hline Non-responder & $90(17.42)$ \\
\hline Relapser & $43(8.33)$ \\
\hline Interruption & $12(2.27)$ \\
\hline \multicolumn{2}{|c|}{ Previous treatment with pegIFN + RBV + Telaprevir or pegIFN + RBV + Boceprevir } \\
\hline Boceprevir & 4 \\
\hline pegIFN + RBV + Telaprevir & 1 \\
\hline \multicolumn{2}{|l|}{ Concomitant pathologies $^{\mathbf{a}}$} \\
\hline Diabetes mellitus type 2 & $86(16.6)$ \\
\hline High blood pressure & $32(6.17)$ \\
\hline COPD & $3(0.57)$ \\
\hline Mediterranean anemia & $32(6.17)$ \\
\hline Rheumatoid arthritis & $8(1.54)$ \\
\hline Psoriasis & $4(0.77)$ \\
\hline Ischemic cardiomyopathy & $41(7.91)$ \\
\hline Chronic kidney failure & $9(1.73)$ \\
\hline Benign prostatic hyperplasia & $57(11)$ \\
\hline Cirrhosis $^{\mathrm{a}}$ & $300(57.9)$ \\
\hline \multicolumn{2}{|l|}{ Esofageal varices $^{a}$} \\
\hline $\mathrm{F} 1$ & $36(12)$ \\
\hline F2 & $15(5)$ \\
\hline F3 & $4(1.3)$ \\
\hline \multicolumn{2}{|l|}{ Child pugh score $^{a}$} \\
\hline Child A & $293(97.6)$ \\
\hline Child B & $7(2.4)$ \\
\hline MELD score $^{b}$ & $8 \pm 1.94$ \\
\hline FIB4 score ${ }^{b}$ & $4.17 \pm 3.27$ \\
\hline Steatosis $^{\text {a }}$ & $102(19.96)$ \\
\hline \multicolumn{2}{|l|}{ Fibroscan $^{a}$} \\
\hline $\mathrm{F} 1$ & $38(7.4)$ \\
\hline F2 & $68(13.1)$ \\
\hline F3 & $112(21.6)$ \\
\hline F4 & $300(57.9)$ \\
\hline
\end{tabular}

Abbreviations: BMI, body mass index; COPD, chronic obstructive pulmonary disease; FIB4, the fibrosis 4 index; MELD, model for end-stage liver disease; pegIFN, pegylated Interferon; RBV, Ribavirin.

${ }^{a}$ Values are expressed as No. (\%).

${ }^{b}$ Values are expressed as mean $\pm \mathrm{SD}$ 

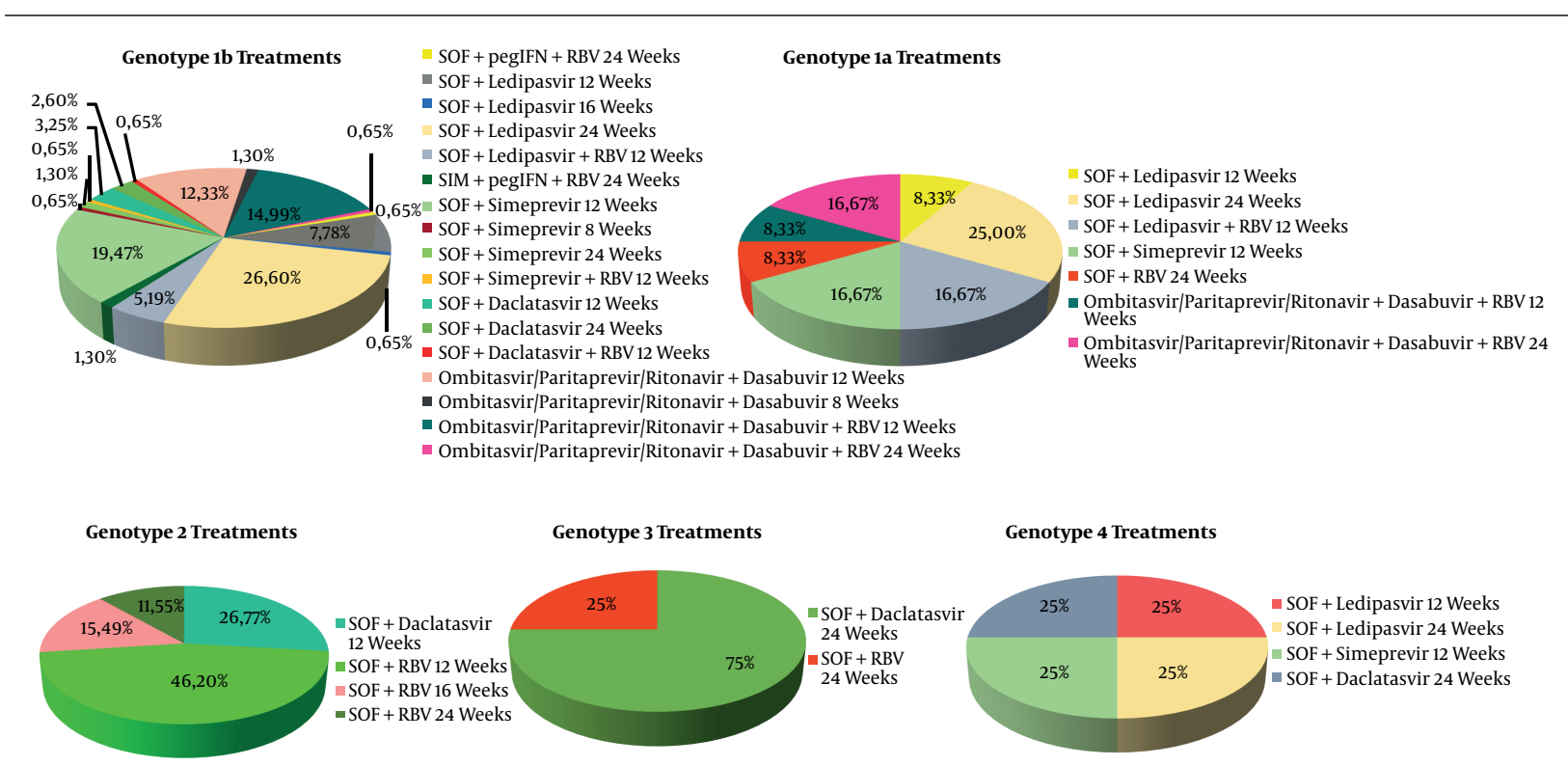

Figure 1. The therapeutic choices for each genotype. We enrolled 518 consecutive patients. Most of them had HCV genotype $1 \mathrm{~b}$ infection. For genotype $1 \mathrm{~b}$, the most prescribed treatment was SOF + Ledipasvir for 24 weeks (26.6\%); for genotype 1a, the most prescribed treatment was SOF + Ledipasvir for 24 weeks (25\%); for genotype 2, the most prescribed treatment was SOF + RBV for 12 weeks (46.11\%); for genotype 3, the most prescribed treatment was SOF + Daclatasvir for 24 weeks (75\%); for genotype 4, we noticed the same distribution of the four prescribed treatment: SOF + Ledipasvir for 12 weeks, SOF + Ledipasvir for 24 weeks, SOF + Simeprevir for 12 weeks, and SOF + Daclatasvir for 24 weeks (25\% each one). Abbreviations: SOF, Sofosbuvir; RBV, Ribavirin; pegIFN, pegylated Interferon.

the beginning of the treatment, an increase in bilirubin and prothrombin time with a significant decrease in albumin serum levels occurred. This patient, as expected, showed positive HCV-RNA in the 12 weeks from the end of the therapy. Other 46 patients treated with Ombitasvir/Paritaprevir/Ritonavir plus Dasabuvir for 12 weeks reached SVR12.

Most of the analyzed population (88.2\%) did not show any adverse effects and all of them occurring were classified as mild (a part of the previously mentioned side effects). The most common adverse effects were a headache (5\%) and weariness (6.3\%). The six patients who did not respond to the treatment underwent resistance genetic tests (two of them are ongoing); later, they were treated with a new therapeutic regimen: one with Ombitasvir/Paritaprevir/Ritonavir plus Dasabuvir for 12 weeks, one with Ledipasvir plus Sofosbuvir for 24 weeks, and two with Sofosbuvir plus Velpatasvir plus RBV for 24 weeks. These patients were middle-aged, had fibrosis F3 or F4 by Fibroscan, and were naive to prior antiviral treatments with the exception of one of them that was treated with pegIFN + RBV. Four of them were affected by genotype $1 \mathrm{~b}$ infection, one by genotype 4 , and one by genotype 2 . All the re-treated patients reached SVR12 except two of them that are waiting for viral resistance test (Tables 2 and 3).

All cirrhotic patients treated with therapeutic reg- imens described did not show during and after the treatment a worsening of model for end-stage liver disease (MELD) score and Child-Pugh score, with the exception of a unique case already pointed out after 30 days from the beginning of the treatment with Ombitasvir/Paritaprevir/Ritonavir plus Dasabuvir plus RBV. Moreover, a statistically significant reduction in fibrosis score index 4 (FIB-4) occurred in 12 weeks from the end of the therapy for the patient who obtained SVR12 (baseline: $4.17 \pm 3.27$; SVR12: $2.13 \pm 1.21 ; \mathrm{P}<0.05)$.

\section{Discussion}

The DAA use has led the international scientific community to participate in a real revolution in approaching the social and health problem of HCV infection, a rare event in medical history for other types of pathologies. The possibility to benefit from simple and tolerable treatments, with an elevated efficacy, has totally changed both the prognosis and the natural history of HCV infection. Viral eradication allowed a progressive reduction in the infection risk among humans, with the exception of particular categories of patients, such as endovenous drug addicts and homosexuals. Moreover, it will cause a clear reduction in HCC incidences, thus allowing us to avoid the onset of 


\begin{tabular}{|c|c|c|c|c|}
\hline DAAs Regimens & SVR12 & Relapse & Failure & $\begin{array}{c}\text { Interruption Due to Adverse Events or Death Not Related } \\
\text { to the Treatment }\end{array}$ \\
\hline SOF + RBV 12 weeks & $30(100)$ & 0 & 0 & 0 \\
\hline SOF + RBV 16 weeks & $10(100)$ & 0 & 0 & 0 \\
\hline SOF $+\operatorname{RBV} 24$ weeks & $15(93.7)$ & 0 & 0 & $1(6.3)$ \\
\hline SOF + Simeprevir 8 weeks & $2(100)$ & 0 & 0 & 0 \\
\hline SOF + Simeprevir 12 weeks & $92(96.8)$ & $3(3.2)$ & 0 & 0 \\
\hline SOF + Simeprevir 24 weeks & $5(100)$ & 0 & 0 & 0 \\
\hline SOF + Simeprevir + RBV 12 weeks & $2(100)$ & 0 & 0 & 0 \\
\hline SOF + Daclatasvir 12 weeks & $32(100)$ & 0 & 0 & 0 \\
\hline SOF + Daclatasvir 24 weeks & $26(100)$ & 0 & 0 & 0 \\
\hline SOF + Daclatasvir + RBV 12 weeks & $2(100)$ & 0 & 0 & 0 \\
\hline SOF + Ledipasvir 12 weeks & $43(100)$ & 0 & 0 & 0 \\
\hline SOF + Ledipasvir 16 weeks & $2(100)$ & 0 & 0 & 0 \\
\hline SOF + Ledipasvir 24 weeks & $127(97.7)$ & 0 & 0 & $3(2.3)$ \\
\hline SOF + Ledipasvir + RBV12 weeks & $20(100)$ & 0 & 0 & 0 \\
\hline Ombitasvir/Paritaprevir/Ritonavir + Dasabuvir 8 weeks & $4(100)$ & 0 & 0 & 0 \\
\hline Ombitasvir/Paritaprevir/Ritonavir + Dasabuvir 12 weeks & $40(100)$ & 0 & 0 & 0 \\
\hline $\begin{array}{l}\text { Ombitasvir/Paritaprevir/Ritonavir + Dasabuvir + RBV } 12 \\
\text { weeks }\end{array}$ & $46(97.8)$ & 0 & 0 & $1(2.2)$ \\
\hline $\begin{array}{l}\text { Ombitasvir/Paritaprevir/Ritonavir + Dasabuvir + RBV } 24 \\
\text { weeks }\end{array}$ & $6(100)$ & 0 & 0 & 0 \\
\hline Simeprevir + pegIFN + RBV 24 weeks & $4(100)$ & 0 & 0 & 0 \\
\hline SOF + pegIFN + RBV 24 weeks & $2(100)$ & 0 & 0 & 0 \\
\hline
\end{tabular}

Abbreviations: pegIFN, pegylated Interferon; RBV, Ribavirin; SOF, Sofosbuvir. ${ }^{a}$ Values are expressed as No. (\%).

\begin{tabular}{|c|c|c|c|c|c|c|c|c|c|}
\hline Sex & Age & Genotype & $\begin{array}{l}\text { Previous } \\
\text { Treatment }\end{array}$ & $\begin{array}{l}\text { First Treatment } \\
\text { Prescribed }\end{array}$ & $\begin{array}{l}\text { Metavir } \\
\text { Score }\end{array}$ & Therapeutic Outcome & Viral Resistance Test & $\begin{array}{c}\text { Second Line Treatment } \\
\text { Prescribed }\end{array}$ & $\begin{array}{c}\text { Therapeutic } \\
\text { Outcome }\end{array}$ \\
\hline $\mathbf{F}$ & 42 & $1 \mathrm{~b}$ & NAIVE & $\begin{array}{l}\text { Ombit asvir/ Paritaprevir/ } \\
\text { Ritonavir + Dasabuvir + RBV } \\
\text { (12 weeks) }\end{array}$ & $\mathrm{F} 4$ & $\begin{array}{l}\text { Interruption due to } \\
\text { worsening of hepatic } \\
\text { function indices }\end{array}$ & NS5A: Y93H & $\begin{array}{c}\text { SOF + Velpatasvir }+ \text { RBV }(24 \\
\text { weeks })\end{array}$ & SVR12 \\
\hline м & 48 & $1 \mathrm{~b}$ & NAIVE & SOF + Simeprevir (12 weeks) & F3 & Relapse & NS5A P58S & $\begin{array}{c}\text { Ombitasvir/ Paritaprevir/ } \\
\text { Ritonavir + Dasabuvir ( } 12 \\
\text { weeks) }\end{array}$ & SVR12 \\
\hline $\mathbf{F}$ & 52 & $1 \mathrm{~b}$ & NAIVE & SOF + Simeprevir (12 weeks) & F3 & Relapse & $\begin{array}{l}\text { No mutations on NS3, NS5A } \\
\text { and NS5B genomic regions }\end{array}$ & SOF + Ledipasvir (24 weeks) & SVR12 \\
\hline M & 51 & 4 & NAIVE & SOF + Simeprevir (12 weeks) & $\mathrm{F} 4$ & Relapse & NS3: D168V; NS5A:Y93H & $\begin{array}{c}\mathrm{SOF}+\text { Velpatasvir }+\mathrm{RBV}(24 \\
\text { weeks })\end{array}$ & SVR12 \\
\hline $\mathbf{F}$ & 68 & 2 & NAIVE & SOF + RBV (24 weeks) & F3 & $\begin{array}{l}\text { Interruption due to } \\
\text { worsening of depressive } \\
\text { disorder }\end{array}$ & Ongoing & - & - \\
\hline $\mathbf{F}$ & 75 & $1 \mathrm{~b}$ & pegIFN + RBV & SOF + Ledipasvir (24 weeks) & F3 & $\begin{array}{l}\text { Interruption due to inguinal } \\
\text { subepidermic appearance of } \\
\text { vescicula }\end{array}$ & Ongoing & - & - \\
\hline
\end{tabular}

Abbreviations: NS5A, nonstructural protein 5 A; NS3, nonstructural protein 3; pegIFN, pegylated Interferon; RBV, Ribavirin; SOF, Sofosbuvir.

a severe pathological condition, treated with unsatisfying therapeutic results still today $(21,22)$.

Despite that these therapeutic approaches allowed obtaining results in terms of public health, questions related to DAA use are yet open. For the complete eradication of
HCV infection, it is necessary to take into account the economical availability to sustain the expenses for follow-up in the areas at the elevated risk of HCV infection, such as Campania (23). Similarly, it is necessary to focus on the possibility of re-infection in patients already treated following 
blood contact after the viral eradication, as well as on the necessity to plan assistance programs to improve the treatment compliance in old people, foreigners, and the poor $(24,25)$.

Out of about 90000 patients treated in Italy until July 2017, 12000 were resident in Campania. Our monocentric trial aimed at producing data of real life on the efficacy and tolerance of DAA antiviral treatment for HCV in a geographical area with a high prevalence of the infection. In this regard, 518 patients were enrolled at theHepatogastroenterology Division of the University of Campania "Luigi Vanvitelli" in Naples (Italy). These patients were candidates for the treatment independently from both genotype and disease stage. For each specific case, the used treatment was chosen according to the current drug availability and clinical recommendations (20). The SVR 12 rate obtained by the ITT analysis was $98.65 \%$. The SVR 12 rate was found to be very elevated, thus confirming the elevated efficacy of these treatments when used according to the clinical practice norms (20).

Only in three patients treated with Sofosbuvir plus Simeprevir for 12 weeks occurred a relapse. This was probably due to the advanced stage of the disease and the suboptimal therapeutic choice that we had available at the time of treatment.

Most of the patients did not have side effects correlated with the treatment; therefore, we were not obligate to interrupt it, with the exception of a few cases. One death was registered during the antiviral treatment due to reasons that were not correlated to it, i.e. a car crash. For other patients, the side effect that led to the therapy interruption was the worsening of major depressive disorder for a patient treated with Sofosbuvir plus RBV for 24 weeks and another patient treated with Sofosbuvir plus Lepidasvir for 24 weeks. Moreover, we observed the inguinal subepidermic appearance of vescicula for a patient treated with Sofosbuvir plus Lepidasvir for 24 weeks. These side events were considered as mild and they were considered independently from antiviral therapy. Only in a unique case of a patient treated with Ombitasvir/Paritaprevir/Ritonavir plus Dasabuvir plus RBV for 12 weeks, who showed a ChildPugh score A5 in pre-treatment, we observed a worsening after 30 days from the beginning of the therapy, related to the increased prothrombin time and bilirubin and significantly decreased albumin. This patient did not show ascites or encephalopathy, and biochemical alterations were normal in two weeks after the therapy interruption. However, the presence of a unique case out of a total of patients with the same therapeutic regimens leads us to confirm the elevated efficacy and the good tolerability of the therapy in patients affected by genotype $1 \mathrm{~b}$ with or without liver cirrhosis (26). In our records, the use of RBV among the different therapeutic schemes used was not associated with a higher incidence of adverse effects. A different consideration must be done on the revaluation of data of SVR12 in relation to the median age of the patients enrolled in our study. The median age was about 66 years, a condition that leads our SVR12 data to a greater satisfaction given the low SVR12 rate obtained in a population with median/high age with regimens characterized by pegylated IFN due to the insufficient tolerance related to it (27).

One limitation of our study is to reflect a situation as the Campania reality with clinical data from one center, which includes a large geographical area of the region, positioning in two prescriptive poles. Another possible limitation could be represented by the imbalance of patients affected by genotype $1 \mathrm{~b}$ compared to other analyzed genotypes. In this regard, we underline how the prevalence of an infection sustained by genotype $1 \mathrm{~b}$ is higher in Campania than by other genotypes. Moreover, the data regarding the route of HCV acquisition were not available. Finally, our outcomes do not allow us to realize a predictive long-term model of post-viral eradication for cirrhotic patients who obtain SVR in order to evaluate the correlation between costs and advantages of these treatments, especially in old age populations.

New antiviral regimens of DAA-based for HCV represent one of the greatest innovations in the scientific context in the last few years. Our prospective observational study confirms the elevated efficacy in terms of SVR12 obtained independently from HCV genotype and disease stage when these treatments are used as the methods of a good clinical practice (20). The results obtained by these types of studies allow us to understand the real social problem regarding HCV in order to obtain a viral eradication in a large part of population resident in the areas with a high prevalence of infection. Only through this strategy will it be possible to limit even more the onset of new cases of infection, consequently the complete elimination of infection in the near future.

\section{Acknowledgments}

We thank Dr. Maddalena Farina for her english assistance.

\section{Footnotes}

Authors' Contribution: Study concept and design: Alessandro Federico and Carmelina Loguercio; acquisition of data: Marcello Dallio, Giuseppe Gerardo Caprio, Gaetano Cotticelli, Pasquale Esposito and Ilario de Sio; analysis and interpretation of data: Alessandro Federico and Marcello 
Dallio; drafting of the manuscript: Alessandro Federico and Marcello Dallio; critical revision of the manuscript for important intellectual content: Alessandro Federico, Marcello Dallio and Carmelina Loguercio; statistical analysis: Marcello Dallio; administrative, technical, and material support: Alessandro Federico, Marcello Dallio, Giuseppe Gerardo Caprio, Gaetano Cotticelli, Pasquale Esposito, Ilario de Sio and Carmelina Loguercio; study supervision: Alessandro Federico and Carmelina Loguercio.

Ethical Considerations: This is a real life study regarding the prescription of HCV antiviral therapy according to the good clinical practice guidelines.

\section{References}

1. Polaris Observatory HCV Collaborators. Global prevalence and genotype distribution of hepatitis $C$ virus infection in 2015: A modelling study. Lancet Gastroenterol Hepatol. 2017;2(3):161-76. doi:10.1016/S24681253(16)30181-9. [PubMed: 28404132].

2. European Union HCV Collaborators. Hepatitis $C$ virus prevalence and level of intervention required to achieve the WHO targets for elimination in the European Union by 2030: A modelling study. Lancet Gastroenterol Hepatol. 2017;2(5):325-36. doi: 10.1016/S2468-1253(17)300456. [PubMed: 28397696].

3. La Torre G, Gualano MR, Semyonov L, Nicolotti N, Ricciardi W, Boccia A. Hepatitis C Virus infections trends in Italy, 1996-2006. Hepat Mon. 2011;11(11):895-900. doi: 10.5812/kowsar.1735143X.767. [PubMed: 22308154]. [PubMed Central: PMC3269058].

4. Marascio N, Liberto M, Barreca G, Zicca E, Quirino A, Lamberti A, et al. Update on epidemiology of HCV in Italy: Focus on the Calabria Region. BMC Infect Dis. 2014;14 Suppl 5. S2. doi: 10.1186/1471-2334-14-S5-S2. [PubMed: 25236184]. [PubMed Central: PMC4160896].

5. Mennini FS, Marcellusi A, Andreoni M, Gasbarrini A, Salomone S, Craxi A. Health policy model: Long-term predictive results associated with the management of hepatitis $\mathrm{C}$ virus-induced diseases in Italy. Clinicoecon Outcomes Res. 2014;6:303-10. doi: 10.2147/CEOR.S62092. [PubMed: 24971024]. [PubMed Central: PMC4069043].

6. Perrone V, Sangiorgi D, Buda S, Degli Esposti L. Disease progression and health care resource consumption in patients affected by hepatitis C virus in real practice setting. Clinicoecon Outcomes Res. 2016;8:5917. doi: 10.2147/CEOR.S108288. [PubMed: 27789966]. [PubMed Central: PMC5072570].

7. Buonomo AR, Scotto R, Pinchera B, Coppola N, Monari C, Macera M, et al. Epidemiology and risk factors for hepatitis $C$ virus genotypes in a high prevalence region in Italy. New Microbiol. 2018;41(1):26-9. [PubMed: 29112765].

8. Coppola N, Pisaturo M, Tonziello G, Sagnelli C, Sagnelli E, Angelillo IF. Efficacy of Pegylated Interferon alpha-2a and alpha-2b in patients with genotype 1 chronic hepatitis C: A meta-analysis. BMC Infect Dis. 2012;12:357. doi: 10.1186/1471-2334-12-357. [PubMed: 23245594]. [PubMed Central: PMC3556138].

9. Ghany MG, Strader DB, Thomas DL, Seeff LB, American Association for the Study of Liver D. Diagnosis, management, and treatment of hepatitis C: An update. Hepatology. 2009;49(4):1335-74. doi: 10.1002/hep.22759. [PubMed: 19330875].

10. Loguercio C, Federico A, Masarone M, Torella R, Blanco Cdel V, Persico $M$. The impact of diet on liver fibrosis and on response to Interferon therapy in patients with HCV-related chronic hepatitis. Am J Gastroenterol. 2008;103(12):3159-66. doi: 10.1111/j.1572-0241.2008.02159.x. [PubMed: 18786125].

11. Federico A, Masarone M, Romano M, Dallio M, Rosato V, Persico M. Rapid virological response represents the highest prediction factor of response to antiviral treatment in HCV-related chronic hepatitis: A multicenter retrospective study. Hepat Mon. 2015;15(6). e18640. doi: 10.5812/hepatmon.15(6)2015.18640. [PubMed: 26286149] [PubMed Central: PMC4532787].

12. Poordad F, McCone JJ, Bacon BR, Bruno S, Manns MP, Sulkowski MS, et al. Boceprevir for untreated chronic HCV genotype 1 infection. $N$ Engl J Med. 2011;364(13):1195-206. doi: 10.1056/NEJMoa1010494. [PubMed: 21449783]. [PubMed Central: PMC3766849].

13. Federico A, Sgambato D, Cotticelli G, Gravina AG, Dallio M, Beneduce F, et al. Skin adverse events during dual and triple therapy for HCVrelated cirrhosis. Hepat Mon. 2014;14(3). e16632. doi: 10.5812/hepatmon.16632. [PubMed: 24734094]. [PubMed Central: PMC3984470].

14. European Association for Study of Liver. EASL clinical practice guidelines: Management of hepatitis $\mathrm{C}$ virus infection. J Hepatol. 2014;60(2):392-420. doi: 10.1016/j.jhep.2013.11.003. [PubMed: 24331294].

15. Jacobson IM, Gordon SC, Kowdley KV, Yoshida EM, Rodriguez-Torres M, Sulkowski MS, et al. Sofosbuvir for hepatitis C genotype 2 or 3 in patients without treatment options. N Engl J Med. 2013;368(20):186777. doi: 10.1056/NEJMoa1214854. [PubMed: 23607593].

16. Kondili LA, Romano F, Rolli FR, Ruggeri M, Rosato S, Brunetto MR, et al. Modeling cost-effectiveness and health gains of a "universal" versus "prioritized" hepatitis $C$ virus treatment policy in a reallife cohort. Hepatology. 2017;66(6):1814-25. doi: 10.1002/hep.29399. [PubMed: 28741307]. [PubMed Central: PMC5765396].

17. Grimaldi E, Della Pepa ME, Martora F, Magliocca P, Iovene MR, Coppola $\mathrm{N}$, et al. Distribution of hepatitis $\mathrm{C}$ virus genotypes and subtypes in the metropolitan area of naples, Italy, in the era of Interferon-free regimens. Intervirol.2017;60(3):82-9. doi:10.1159/000481821. [PubMed: 29161710].

18. Hutchison C, Kwong A, Ray S, Struble K, Swan T, Miller V. Accelerating drug development through collaboration: The Hepatitis C Drug Development Advisory Group. Clin Pharmacol Ther. 2014;96(2):162-5. doi: 10.1038/clpt.2014.113. [PubMed: 24853733].

19. Lontok E, Harrington P, Howe A, Kieffer T, Lennerstrand J, Lenz O, et al. Hepatitis $C$ virus drug resistance-associated substitutions: State of the art summary. Hepatol. 2015;62(5):1623-32. doi: 10.1002/hep.27934 [PubMed: 26095927].

20. European Association for Study of L. EASL recommendations on treatment of hepatitis C 2015. J Hepatol. 2015;63(1):199-236. doi 10.1016/j.jhep.2015.03.025. [PubMed: 25911336].

21. Li DK, Chung RT. Impact of hepatitis C virus eradication on hepatocellular carcinogenesis. Cancer. 2015;121(17):2874-82. doi: 10.1002/cncr.29528. [PubMed: 26079399]. [PubMed Central: PMC4545677].

22. Scott N, Stoove M, Wilson DP, Keiser O, El-Hayek C, Doyle J, et al. Eliminating hepatitis $\mathrm{C}$ virus as a public health threat among HIVpositive men who have sex with men: A multi-modelling approach to understand differences in sexual risk behaviour. I Int AIDS Soc. 2018;21(1). doi: 10.1002/jia2.25059. [PubMed: 29314670]. [PubMed Central: PMC5810343].

23. Asselah T, Marcellin P, Schinazi RF. Treatment of hepatitis C virus infection with direct-acting antiviral agents: 100\% cure? Liver Int. 2018;38 Suppl 1:7-13. doi: 10.1111/liv.13673. [PubMed: 29427484].

24. Cooper CL, Hatashita H, Corsi DJ, Parmar P, Corrin R, Garber G Direct-acting antiviral therapy outcomes in canadian chronic hepatitis C telemedicine patients. Ann Hepatol. 2017;16(6):874-80. doi: 10.5604/01.3001.0010.5277. [PubMed: 29055923].

25. Monllor-Nunell MT, Sanchez-Lloansi M, Dosal-Galguera A. Direct antiviral treatment in patients with hepatitis $C$ virus: Implementation of a nurse telephone consultation. Enferm Clin. 2017;27(6):387-91. doi 10.1016/j.enfcli.2017.09.005. [PubMed: 29074167].

26. Lawitz E, Makara M, Akarca US, Thuluvath PJ, Preotescu LL, Varunok P, et al. Efficacy and safety of ombitasvir, paritaprevir, and ritonavir in an open-label study of patients with genotype $1 \mathrm{~b}$ chronic 
hepatitis C virus infection with and without cirrhosis. Gastroenterol.2015;149(4):971-80 e1. doi:10.1053/j.gastro.2015.07.001. [PubMed: 26170136].

27. Roeder C, Jordan S, Schulze Zur Wiesch J, Pfeiffer-Vornkahl H, Hueppe
D, Mauss S, et al. Age-related differences in response to peginterferon alfa-2a/Ribavirin in patients with chronic hepatitis $\mathrm{C}$ infection. World J Gastroenterol. 2014;20(31):10984-93. doi: 10.3748/wjg.v20.i31.10984. [PubMed: 25152602]. [PubMed Central: PMC4138479]. 